www.jmscr.igmpublication.org Impact Factor 5.244

Index Copernicus Value: 5.88 ISSN (e)-2347-176x ISSN (p) 2455-0450 crossref DOI:_http://dx.doi.org/10.18535/jmscr/v4i6.05

\title{
Challenges of Clinical Psychology and Penitentiary System: Recidivism versus Reformation
}

\author{
Authors \\ Hena Fatma', Dr Munawwar Husain ${ }^{2}$ \\ ${ }^{1}$ MA (Clinical Psychology), PG Dip in Criminology and Criminal Administration, Ph.D (Scholar) \\ Research Scholar, Department of Psychology, Aligarh Muslim University, Aligarh, India \\ ${ }^{2}$ MBBS, MD, BND, MNAMS, PG Dip in Criminology and Criminal Administration \\ Professor, Fmr Medical Superintendent \& Principal, School of Nursing, Department of Forensic Medicine, \\ Aligarh Muslim University, Aligarh, India \\ Corresponding Author \\ Hena Fatma \\ Email: hena.ali01@gmail.com, Mobile No.:07080553954
}

\begin{abstract}
Worldwide, prison system has been established to in incarcerate offenders with two fold objectives. One to segregate the convict from the society, and two to give him sufficient time to pore over repeatedly about his misdeed and demonstrate amplified inclination to reform himself. Since time immemorial prison system has been adjudged to be reformative in nature. Put plainly the convict as a criminal should be put behind bars. However, studies have demonstrated that with the current punitive system the rate of recidivism is quite high which indicate that the penitentiary system has failed in its objective. New experiments were done to tone up the prison and let the prisoners contribute better and fully in the society. As an alternate mechanism the open jail system was mooted. In this paper the author has undertaken a contrasted analysis between rate of recidivism in high security prison and relatively open system of incarceration. Bolivian prison system is supposed to be most relaxed system in this world. Therefore, in the current paper this prison system would be examined and quoted.

Keywords: Penitentiary system, open jail, retributive, reformation, Bolivian jail system
\end{abstract}

\section{Background of the study}

"Crime is the outcome of a diseased mind and jail must have an environment of hospital for treatment and care." (Mahatma Gandhi)

Indian prison system and high security

One of the main objectives of incarceration, right from the inception of this concept in a sovereign state, was to curtail the liberty of movement and the freedom of initiative of a person, if he was found to have violated the established law of the land and authority to change the current prison laws and rules and regulations in Indian prison system. ${ }^{[1]}$ Prisons took shape as institutions of state retribution as a natural outcome of the materialization of this objective. Resultant segregation of offenders from the society, and the 
obligation of prison guards to restraint their movement against escape from lawful custody, constrained the architects of prison buildings to burden them with high walls, narrow galleries, labyrinths, shutters, locks, chains, fetters, shackles, cells and places of solitary confinement. This physical structure of prisons and the archaic rules of management of these punitive institutions endowed them with a cover of obscurity in which fundamental human rights could be unofficially violated and officially denied. There were no windows and curtains which may be lifted up and notice what had been going inside the prison.

Prisons grew to be places of low visibility where inhuman and even cruel conditions could prevail. The possibility of inflicting injury and injustice on inmates always lurked in these closed institutions. State supervision over day-to-day happenings within such institutions became a mere formality and the surveillance of the society was conspicuous by its absence.

In spite of the fact that prison system has, during the past some decades, undergone a massive change both in its objectives and in its physical structure, the basic character of prisons -- as closed institutions with little public scrutiny -continues to this day.

The need for non-government intervention in prisons was recognized as early as 1894 when the Prisons Act accepted that a system of visitors would be of value in providing humanitarian aid to prison inmates secluded from the society. The Cardew Committee appointed by the British Government in that year devoted a whole chapter to making this system more effective and efficacious. ${ }^{[2]}$

As a result the concept of non-government intervention in the management of prisons was for the first time conceived in The Prisons Act of 1894. Although this concept did not find place in the body of main provisions of the Act, but in Section 59, which speaks of powers to frame rules consistent with this Act, the State Governments were empowered to make rules for the appointment and guidance of visitors of prisons in sub-section (25). The present provisions for official and non- official visitors in Prison Manuals of various states are the result of this sub-section (25) of section 59 of The Prisons Act of 1894.

The first comprehensive work of studying the prison conditions and of making remarkably suitable recommendations for the reformation of both prison was undertaken. Prison is just one of a number of sanctions able to use the courts to deals with those who commit criminal offences. Imprisonments today is ably the harshest sanction, but this has not always been the case. The first $19^{\text {th }}$ century represented a watershed in the history of state punishment. Capital punishment was now regarded as an inappropriate sanction for many crimes. The shaming sanctions, like the stocks, were regarded as outdated. By mid-century, imprisonment had replaced capital punishment for most serious offences except for that of murder.

The $19^{\text {th }}$ century was seen the birth of the state prison. The first national penitentiary was completed at mill bank in London, in $1816 .{ }^{[3]}$ It holds 860 prisoners, kept in separate cells, and although associated with other prisoners they were allowed was allowed to intermingle during the day. Work in san Pedro prison was mainly centered on simple tasks such as picking "coir" (tarred rope) and weaving.

In 1842 Penton Ville prison was built using the Panoption design; this prison is still used today. ${ }^{[4]}$ That prison considered the risk factors of suicide in prisoners. Suicide is often the single most common cause of death in correctional settings. It is the third leading cause of death in U.S. prisons and the second in jails. ${ }^{[5]}$ Its rate in prisons ranged from 18 to 40 per 100,000 during the past three decades. ${ }^{[6,7,8]}$ Jails and prisons are repositories for unprotected groups that are traditionally among the highest risk for suicide. Few risk factors may be common to both the general public and prisoners. But there are many factors related to suicide in prisons. Being imprisoned is itself a stressful event for even healthy inmates as it deprives the person of important resources. This 
background of the study is Indian prison system high suicide rate. And then identifies the pattern and occurrence of its risk factors. Its seen that prison inmates have higher suicide rates than their community counterparts, ${ }^{[9]}$ and there is some evidence that rates are increasing even in places where the numbers of prisoners are decreasing. ${ }^{[10]}$ Pretrial detainees have a suicide attempt rate of about 7.5 times, and sentenced prisoners have a rate of almost six times the rate of males in prison compared to that of general population. ${ }^{[11]}$ The suicide rate is higher within the offender group even after their release from prison. ${ }^{[12]}$ In Indian prison system,suicide data from prisons is sparse. Tihar is the central jail of India with the inmate population of around 13000 at any given time. When prison data of last 10 years reviewed, it secreted that one complete suicide occurred every year except in the year 2004 and 2010 when four suicides occurred in each year. In the current year two 'completed' suicides have been recorded in four months. Most probably suicide rate has increased over last year. Reason behind this may be ongoing stress related to court proceedings and anticipation of unfavorable outcome of trial. But the parasuicides in prison is generally categorized as non-lethal self-injury, and self- harming similar to self-mutilation. All self-harming acts may be seen on a continuum of severity, not as distinct problems, since the motivation for self-injurious behavior is the same for both attempters. And many attempt suicide before they are successful. ${ }^{[13]}$ Some inmates attempt suicide with no intention of ever completing the act, while others thinking of using more lethal methods until they are successful.

In general, prior suicide attempts accentuate the risk of suicide in future. From 45- $63 \%$ of inmates who commit suicide have attempted it before. $^{[14],[15]}$

\section{Risk factors:}

Risk factors such as drug abuse, unemployment, interpersonal conflicts, harassment by the prison staff, and mental illness are common in the general public and prisons. There are following some risk factors related to prisons related and clinical disposition.

\section{Socio-demographic factors}

Studies carried out have demonstrated more than half of all inmates who commit suicide in prisons are between 25 and 34 years of age. ${ }^{[16,17]}$ They are often single with no job or family support. Very young prisoners (below age 21) are especially at risk factors. In fact, the suicide rate among juvenile offenders placed in adult detention facilities almost eight times greater than the rate in juveniles housed in juvenile detention facilities. ${ }^{[18]}$ Upper socioeconomic status and high degree of social and family integration before incarceration increase the risk of suicide in prison. ${ }^{[19]}$

\section{Clinical factors}

\section{Psychiatric disorders}

There are psychiatric disorders among suicidal inmates ranging from 33-95 \%. ${ }^{[20]}$ Depressive disorders are more related to suicide than other psychiatric illness. ${ }^{[21]}$ Depression, hopelessness and helplessness seem to be the two most common psychological states at the time of a suicidal act. ${ }^{[23]}$ Hopelessness and suicide have a stronger correlation than do depression and suicide. Ivan Pavlon and Carl Jang ${ }^{\text {[24] }}$ developed a multivariate model to suicide by inmates studying the relationship between depression, helplessness, hopelessness, social desirability and other factors. Anxiety experienced by inmates at sometimes of incarceration, particularly on entry into the prison or just before release, may act as a risk factor.

\section{Personality disorder and psychosocial stressors}

Antisocial personality disorder is common to suicide risk factor. And Borderline personality disorder increases the risk for suicide attempts and completions due to poor interpersonal ability, impulsivity, and affective instability. Impulsive suicide attempters under intoxication are more than common among arrestees. ${ }^{[25]}$ Psychosocial stressors like marital separation, divorce, ${ }^{[26]}$ or death of a loved one may precipitate serious suicide attempts. A prisoner is not usually able to participate in rituals associated with the funeral of 
a loved one. Loss or absence of one or both parents for more than 12 months before the age of 15 is related with attempted suicide. ${ }^{[27]}$ Other risk factors include losing contact with one's children, inability to communicate due to language barriers. ${ }^{[28]}$ Other risk is that substance abuse influence of an illegal drug heightens the risk of self- harm $f$ self-harm. ${ }^{[2]}$ The risk of suicide is more than highest opiate dependents who also have psychiatric disorders. However, when drug abusers are incarcerated, the ensuing forced abstinence and no having coping skills due to years of dependency may precipitate suicidal thoughts.

\section{Trial status related factors}

\section{Pre-trial inmates}

Pre-trial inmates who commit suicide are generally young (20-25 years), unmarried male and first time offenders who have been arrested for minor, usually substance related, offences. They are typically intoxicated at the time of their arrest and commit suicide at an early stage of their confinement, ${ }^{[30]}$. A second period of risk for pretrial inmates is near the time of a court appearance, especially when a guilty verdict and harsh sentencing may be anticipated. A great deal of all jail suicides occurred within three days of a court appearance. [31]

\section{Sentenced Prisoners}

The sentenced prisoners who commit suicide in prison are generally older than 30-35 years, violent offenders, and usually committing suicide after staying for long time in custody. (Their suicide may be related to institutional conflicts with other inmates or with the administration, a family conflict or breakup, or a negative legal disposition such as loss of a denial or appeal. Incarceration is loss of freedom, loss of family and social support, fear of the unknown, fear of physical or sexual violence, uncertainty and fear about the future, and guilt over the offence, and fear or stress related to poor environmental conditions.

We can say that the United States has less than 5 percent of the world's population but it has almost a quarter of the world's prisoners. Actually, the United States leads the world in producing prisoners, a reflection of a relatively recent and now entirely distinctive American approach to crime and punishment. Americans are locked up for crimes - from writing bad checks to using drugs - that would rarely produce prison sentences in other countries. And in particular they are kept incarcerated far longer than prisoners and other nations. ${ }^{[32]}$

Criminologists and legal scholars in other industrialized nations say that they are mystified and appalled by the number and length of American prison sentence.

India, which is four times more populous than the United States, is a distant second, with 1.6 million people in prison. (That number excludes hundreds of thousands of people held in administrative detention, most of them in India's extrajudicial system of re-education through labor, which often singles out political activists who have not committed crimes.) ${ }^{[33]}$

Criminologists and legal practitioners here and abroad views to a risk factors to explain America's extraordinary incarceration rate: higher levels of violent crime, harsher sentencing laws, a legacy of racial turmoil, a special fervor in combating illegal drugs, the American temperament, and the lack of a social safety. Even democracy plays a role, as judges - many of whom are elected, another American anomaly - yield to populist demands for justice. Whatever the reason, the gap between American justice and that of the rest of the world is very large and growing.

"In no country is criminal justice administered with more than mildness in the United States," Alexis de Tocqueville, who toured American penitentiaries in 1831, wrote in "Democracy in America." ${ }^{[34]}$ Nowadays, the state prison systems in the United States do not act as efficient systems. As an example of, they act as detention centers that only serve to house offenders in between crimes. I believe that the main reason for the high rates of recidivism in prisons can be pointed to a relation with the high rates of mental 
disease and mental illness in criminal offenders; the terms of imprisonment serve to intensify mental illness and induce psychological pains, and reducing the ability of offenders upon release to become contributing members of society. As a result, once an offender is no longer incarcerated the way of life he/she knows is a return to their former deviant behaviors. This research will help to create a larger, and much necessary for psychology within the walls of the criminal justice system, and, will also serve to decrease recidivism rates in the community. ${ }^{[35]}$

It is my point of view that the criminal justice system is in need of reformation. The government prison model is give one of the better serviceafter incarceration. While government prisons undoubtedly necessary to undergo some reformation, it is not as dire as require for reformation in the state prison system. I would like to lay out a plan for the Bolivian san Pedro prison system that amplifies the government prison system's small scale ideas into ones that can reach thousands of offenders, and prove that community support can be garnered for such a prison. The Bolivian prison systems, is the largest prison in $\mathrm{La} \mathrm{Paz}$, Bolivia renewed for being a society within itself. Significantly different from most correctional facilities, inmates at san Pedro have jobs inside the community, buy or rent their accommodation, and often live with their family members. The sales of cocaine base to visiting tourists gives those inside an important income and an unusual amount of freedom within the prison walls. Elected leaders enforce the law of the community, common though stabbing. The prison is have to approximately 1,500 inmates (not including the women and children that live inside the walls with their committed husbands), with additional guest staying in the prison hotel. [36,37] and then creation of vocational and job training programs during incarceration, a reformed education system, a shift in the allocation of funds from education to a budget for parole officers and community treatment centers, and a creation of an Employment opportunity
Community. While it will be challenging, in the long run I feel it will prove to be highly effective for the Indian Prison System. But - Due to lack of governmental resources, the review of recidivism in Bolivian prison system is extremely difficult as comparison to Indian prison system and the U.K prison system. The particular circumstances in which drug trafficking is carried out in Bolivia are marked by the rural and urban nature of the production of cocaine sulfate and cocaine hydrochloride throughout the country. ${ }^{[38]}$ This means that unlike in the centers of consumption, where micro trafficking is related to "problematic consumption," in Bolivia, involvement in manufacture and transport is related to poverty and unemployment. This is a reality that has extended search out the country and that finds expression, in concentrated design, in each prison.

\section{Recidivism versus Reformation}

Recidivism is one of the most important concepts in criminal justice. It refers to a person's relapse into criminal behavior, often after the person receives sanctions or intervention for a previous crime. Recidivism is measured by criminal acts that resulted in rearrests, reconviction or return to prison with or without a new sentence during a three-year period the prisoner's release. ${ }^{[39]}$ Bureau of Justice Statistics studies have found high rates of recidivism among released prisoners. ${ }^{[40]}$ The first author has identified recidivism for 18 countries. Of the 20 countries with the largest prison populations, only 2 reported repeat offending high rates. The most commonly reported outcome was 2-year reconviction high rates in prisoners. High rates of criminal recidivism are reported to be as high as $50 \%$ in many jurisdictions, and, recorded crime rates in the general population, have not declined in recent years. ${ }^{[41]}$ Recidivism is refers to relapse of criminal behavior, which can include a range of outcomes, including rearrests, reconviction, and re-imprisonment. Prisoners represent a high-risk group compared to other offenders with huge associated costs and a large contribution to overall societal criminality and violence. I can say that 
recidivism rates are high prison system may actually differ from UK or other countries and may be secondary to many risk factors. The threshold for incarceration, the range and quality of intra-prison programs, and investment in the prison medical services, particularly those targeting drug and alcohol problem and other psychiatric disorders. ${ }^{[42]}$ And consider structural or service-related interventions that can be trialed to reduce reoffending high rates. I can say that all men are born and endowed by their creator with some basic rights. These rights are mainly rights to life and liberty but if any person doesn't comply with ethics of the society that person is deprived of these rights with proper punishment. Many experts believe that the main objective of prisons is to bring the offenders back to the mainstream of the society. Various workshops had been organized by the state government in collaboration with NGO`s or rehabilitation to bring reforms in the current prison systems. Consequently, high punitive labor with no regards for the human personalities a severe punishment were the main basic of prison treatment. More than $40 \%$ prison offences have been listed in the jail of many states and any infraction was visited by quite a few barbaric punishments.

Gradually the objective of imprisonment changed from mere deterrence to deterrence reformation. This led to the abandonment of some of the barbaric punishment of the system of awards for good work and conduct in the form of remission review of sentences, wages prison labor, treatment in open conditions, parole, furlough, and other facilities. The improvement in prison conditions will bring concrete changes resulting in rehabilitation of offenders. Prison are known to have existed throughout history originally the dangerous fold castles were used for confining enemies and rivals for enforcing on them the conditions of release.

But this was private or political use of prisons system. Later, they were used for detaining offenders while awaiting trial or until such time as punishment was meted out. It was believed that rigorous isolation and custodial measures would reform the offenders. However, this expectation and often imprisonment had the opposite effect.

The prison system high security and prison reform shows that there are nine major problems which afflict the system and which necessary to immediate attention are:

- Overcrowding

- Delay in trial

- Torture and mental illness treatment

- Neglect of health and hygiene

- Insubstantial food and inadequate clothing

- Prison vices

- Deficiency in communication

- Streamlining of jail visits

- Management of open-air prison.

It is my belief that the criminal justice system is in necessary of reformation. But the government prison model is one that provides better service both during and after incarceration. While government prisons undoubtedly necessary to undergo some reformation, it is not as dire as the need for reformation in the state prison system. The existing prison system is not completely the deboned is not system. It does produce reformed character, however, when it's come to analysis rate of recidivism versus reformation. The statistical present a sorry state with the scale tilting in favor of recidivism.

\section{Conclusion}

The Bolivian system of prison, which is open prison system to an exhausted limit present an hope of oasis, among the wilderness of bleak, global penitentiary system. A time has come to observe and examine the working of Bolivian prison system pick out salubrious points of administration. The reformation is $117.4 \%$ which is considerably higher from the other standard system of prison in the world.

\section{References}

1. Text and Photograph: Rafeal Estefania, BBC Munda“'India- The Penal System'. Country data.com. Retrieved 4 June 2013. 
2. All India Committee On Jail Reforms (1980-83).

3. “Millbank Prison', Handbook of London, 1850 And Evans 1982,p. 249

4. Metzner JL: Class action litigation in correctional psychiatry. J Am Acad. Psychiatry Law 2002; 30: 19-29.

5. Lester D: Prison suicide rates by state from 1984-1993. Psychology Rep 1998; 83: 514.

6. Anno BJ: Patterns of suicide in the Texas Department of Corrections. J Prison Jail Health 1985; 5: 82-93.

7. Salive ME, S. GS, Brewer TF: Death in prison: changing mortality patterns among male prisoners in Maryland, 1979-87. Am J Public Health 1990; 80 : 1479-80

8. Snow L, Paton J, Oram C, Teers R. Selfinflicted deaths during 2001: an analysis of trends. The British Journal of Forensic Practice, 2002; 4(4): 3-17.

9. Fruehwald S, Frottier P. Suicide in prison. Lancet, 2005; 366: 1242-1244.

10. Jenkins R, Bhugra D, Meltzer $\mathrm{H}$, et al. Psychiatric and social aspects of suicidal behaviour in prisons. Psychol Med 2005; 35: 257-269.

11. Pratt D, Piper M, Appleby L, Webb R, Shaw J. Suicide in recently released prisoners: a population-based cohort study. Lancet 2006; 368: 119-123.

12. Haycock J: Capital crimes: suicides in jail. Death Stud 15:41 Liebling A: Suicides in young prisoners: a summary. Death Stud 1993; 17:

13. Kerkhof AJ, Bernasco W: Suicidal behavior in jails and prisons in the Netherlands: incidence, characteristics and prevention. Suicide Life Threat Behav 1990; 20: 123-37.

14. Fruehwald S, Eher R, Frottier P: What was the relevance of previous suicidal behavior in prison suicides? Can J Psychiatry 46:763, 2001.
15. He XY, Felthous AR, Holzer CE, et al: Factors in prison suicide: one year study in Texas. J Forensic Sci 2001; 46: 896-901.

16. Daniel AE, Flemming J: Suicides in a state correctional system 1992-2002. J Correct Health Care 2006; 12: 24-35.

17. Topp DO: Suicide in prison. $\mathrm{Br} \mathrm{J}$ Psychiatry 1979; 134: 24-7.

18. Novick LF, Remmlinger E: A study of 128 deaths in New York City correctional facilities (1971-1976): implications for prisoner health care. Med Care 1978; 16: 749-56.

19. Flaherty MG: An assessment of the national incidence of juvenile suicide in adult jails, lockups and juvenile detention centers. Community Research forum, prepared for the U.S. Department of Justice. Urbana- Champaign, IL: University of Illinois, 1980.

20. Bourgoin N: Mortality due to suicide in prison. Rev EpidemiolSantePublique 1993; 41: 146-54.

21. White TW, Schimmel DJ, Frickey R: A comprehensive analysis of suicide in federal prisons: a fifteen-year review. J Correct Health Care 2002; 9: 321-45.

22. Redding RE: Depression in jailed women defendants and its relationship to their adjudicative competence. J Am Acad Psychiatry Law 1997; 25: 105-19.

23. Ivanoff A, Jang SJ: The role of hopelessness and social desirability in predicting suicidal behavior: a study of prison inmates. J Consult Clinical Psychol 1991; 59: 394-9.

24. Felthous AR: Preventing jailhouse suicide. Bull Am Acad Psychiatry Law 1994; 22: 477-88.

25. Kerkhof AJ, Bernasco W: Suicidal behavior in jails and prisons in the Netherlands: incidence, characteristics and prevention. Suicide Life Threat Behav 1990; 20: 123-37. 
26. Sinha R, Easton C: Substance abuse and criminality. J Am Academic Psychiatry Law 1999; 27: 513-26

27. Shaw J, Baker D, Hunt IM, Moloney A, Appleby L. Suicide by prisoners: national clinical survey. Br J Psychiatry, 2004; 184: 263-267.

28. Marcus P, Alcabes P. Characteristics of suicides by inmates in an urban jail. Hosp Commun Psychiatry 1993; 44: 256-261.

29. United States Department States, 2011 Country Reports On human Rights Practice- Bolivia, 24 May 2012.

30. Johri, Vikram, "Alexia de Tocqueville: The first French Critic of the US', The Christian Sceince Monitor. Retrieved 22 April 2011.

31. American Expectation: inmates Courts in US Dwarfs Other Nations, The New York Times. April 22, 2008: page, Section A, Front Page.

32. Garner, A. (2008). Recidivism Rates Compared 2005-2007. Indianapolis: Indiana Department of Correction.

33. Estefania, Rafael: "Photo Journal: inside Bolivia Jail."' BBC Mundo. Retrieved 2008-12-19

34. Young, Rusty (4 october 2003). "BoliviaSan Pedro.' ABC Outline. Retrieved 2008-12-19

35. Estefania, Rafael: "Photo Journal: inside Bolivia Jail.' BBC Mundo. Retrieved 2008-12-19

36. Durose, Mattew R., Alexia D. Cooper, and Howard N. Snyder, Recidivism of prisoners Released in 30 states in 2005, Pattern from 2005 to 2010, Bureau of Justice Statistics Special report, April 2014, NCJ 244205.
37. Mc- Guire J, Bilby CA, Hatcher RM, Hollin CR, Hounsome j, Palmer EJ, Evaluation of structure cognitivebehavioral treatment programme in reducing criminal recidivism. $\mathrm{J}$, exp. Criminal. 2008; 4(1):21-40.

38. Ministry of justice. Compendium of reoffending statistics and analysis. London: Ministry of justice 2012.

39. Andersem SN, Skardhamar T. Pick a number: Mapping recidivism measure and their consequences Oslo. Statistics Norway Discussion Papers; 2014

40. Durose, Mattew R., Alexia D. Cooper, and Howard N. Snyder, Recidivism of prisoners Released in 30 states in 2005, Pattern from 2005 to 2010, Bureau of Justice Statistics Special Report, April 2014, NCJ 244205. 